WellBeing International

WBI Studies Repository

7-2011

\title{
Mutual Mother-Offspring Vocal Recognition in an Ungulate Hider Species (Capra hircus)
}

\author{
Elodie F. Briefer \\ Queen Mary University of London \\ Alan G. McElligott \\ Queen Mary University of London
}

Follow this and additional works at: https://www.wellbeingintlstudiesrepository.org/acwp_asie

Part of the Animal Studies Commons, Comparative Psychology Commons, and the Other Animal Sciences Commons

\section{Recommended Citation}

Briefer, E., \& McElligott, A. G. (2011). Mutual mother-offspring vocal recognition in an ungulate hider species (Capra hircus). Animal cognition, 14(4), 585-598.

This material is brought to you for free and open access by WellBeing International. It has been accepted for inclusion by an authorized administrator of the WBI Studies Repository. For more information, please contact wbisr-info@wellbeingintl.org.

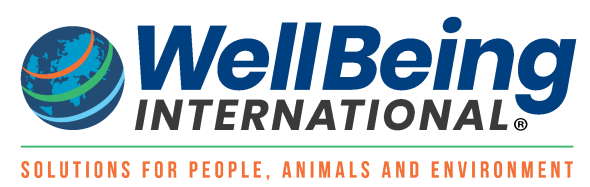




\title{
Mutual Mother-Offspring Vocal Recognition in an Ungulate Hider Species (Capra hircus)
}

\author{
Elodie Briefer and Alan G. McElligott \\ Queen Mary University of London
}

\section{KEYWORDS}

acoustic analysis, antipredator strategies, follower, goat, hider, playback experiment, vocal communication

\section{ABSTRACT}

Parent-offspring recognition can be essential for offspring survival and important to avoid misdirected parental care when progeny mingle in large social groups. In ungulates, offspring antipredator strategies (hiding vs. following) result in differences in mother-offspring interactions, and thus different selection pressures acting on the recognition process during the first weeks of life. Hider offspring are isolated and relatively stationary and silent to avoid detection by predators, whereas follower offspring are mobile and rapidly mix in large social groups. For these reasons, hiders have been suggested to show low offspring call individuality leading to unidirectional recognition of mothers by offspring and followers high offspring call individuality and mutual recognition. We hypothesised that similar differences would exist in hider species between the hiding phase (i.e. unidirectional recognition) and the phase when offspring join social groups (i.e. mutual recognition). We tested these predictions with goats (Capra hircus), a hider species characterised by strong mother-offspring attachment. We compared the individuality of kid and mother calls, and the vocal recognition ability, during the early phase of life when kids are usually hidden and later when kids have typically joined social groups. Contrary to our predictions, we found that both kids and mothers had individualised contact calls and that mutual recognition existed even during the hiding phase. The large differences in the duration of the hiding phase and in the rate of mother-offspring interactions (possibly partially driven by domestication in some species) probably cause variations among hider species in the mother-offspring recognition process.

\section{Introduction}

Studying the link between vocal signals and species ecology can help understand how animal communication evolves. When individual recognition benefits both senders and receivers, senders should develop distinctive signals of identity and receivers accurate mechanisms of recognition (Tibbetts and Dale 2007). Evidence is now increasing for a link between ecological constraints (e.g. group size) and both the degree of individuality of vocal signals (encoding of individual identity) and vocal recognition processes (decoding of individual identity; Aubin and Jouventin 2002; Pollard and Blumstein 2011).

Individual recognition is crucial between parents and offspring in species providing directed parental care, in order to reduce confusion over reproductive investment (Trivers 1972). In social species, vocal cues are particularly important so that mothers and offspring can find each other from a distance after long periods of separation and/or within large groups of unrelated offspring and adults (e.g. Atlantic Walrus, Odobenus rosmarus rosmarus, Charrier et al. 2010; Australian sea lion, Neophoca cinerea, Pitcher et al. 2010; sheep, Ovis aries, Se be et al. 2007). The parent-offspring vocal recognition process can be unidirectional (recognition of the parents by the offspring only or of the offspring by the parents only) or mutual (both parents and offspring recognise each other). Unidirectional recognition of parents by offspring seems to be linked to a low probability of confusion in species where offspring remain stationary and separated from conspecifics (Medvin and Beecher 1986). By contrast, mutual recognition may be required in species in which mobile progeny rapidly mingle in colonies or groups (Stoddard and Beecher 1983). 
In ungulates, mother-offspring relationships are influenced by two main strategies for predator avoidance: hiding and following (Caro 2005). To avoid predation, hider offspring lie concealed in vegetation during the first weeks after birth, and before joining social groups, whereas followers join their mothers soon after birth and rely on fleeing and maternal and group defence. These two strategies cause considerable differences in the interactions between mothers and offspring during the first weeks of life. In hiders, mothers and offspring are usually separated and interact only a few times per day during nursing events. Follower offspring usually remain close to their mothers and interact often (Lent 1974). For these reasons, predator avoidance strategies have been hypothesised to have an impact on mother-offspring vocal communication (Torriani et al. 2006), at the level of both the encoding of individual identity in calls and the associated vocal recognition.

In hider species, females memorise the approximate locations where their offspring are hidden and isolated and call to initiate nursing bouts (Lent 1974; Torriani et al. 2006). Hence, there is little selection pressure on offspring calls to be individualised or on mothers to vocally recognise them. Offspring, however, have to be able to recognise the calls of their own mothers to avoid being detected by predators by leaving their hiding place when hearing a different adult female call. Hider species are thus expected to show low individuality in offspring calls and strong individuality in mother calls. This leads to unidirectional recognition of mothers by offspring, at least during the early life of offspring (fallow deer, Dama dama, Torriani et al. 2006). By contrast, mothers and offspring of follower species live in groups with other same-age conspecifics (Fisher et al. 2002). In such species, strong individuality in both mother and offspring calls and mutual vocal recognition seem crucial to maintain motheroffspring contact and avoid misdirected maternal care (e.g. sheep, Se be et al. 2007). It is also possible that similar differences exist for hiders between the phase when offspring are hidden and the phase when they have joined social groups. Low offspring call individuality and unidirectional recognition of mothers by offspring should exist during the hiding phase, when there is little or no selection pressure for vocal recognition, followed by higher offspring call individuality and mutual recognition once offspring mingle in social groups. These potential differences between the two phases have never been investigated in a hider species. Furthermore, research needs to be extended and tested with ungulates that vary in their ecology, vocal repertoires and social complexity, in order to determine whether the dichotomy in mother-offspring vocal recognition systems (unidirectional vs. mutual) is more widespread.

The aims of the present study were to investigate potential differences in the individuality of calls and motheroffspring vocal recognition ability, between the hiding phase and the phase when offspring had joined social groups, in a hider ungulate, the goat. Female goats give birth in isolation to precocial kids, away from other individuals. In feral goats, kids stay hidden in vegetation for up to 6 weeks old (McDougall 1975). In captive domestic goats, this hiding behaviour is shorter (4-7 days) but also observed even under intensive farm management conditions when provided with appropriate hiding sites (Lickliter 1984). After the hiding phase and until weaning, kids follow their mothers in large groups with other offspring of similar ages and occasionally form cre`ches (O’Brien 1988).

The exclusive care provided by mother goats to their own offspring requires a recognition process (Poindron et al. 1993). At short distances, the mother-offspring bond relies primarily on olfactory cues acquired just after parturition (Lickliter and Heron 1984). Long-range mutual recognition develops in the first days following birth (Lenhardt 1977; Addae et al. 2000), and other sensory modalities such as vision and hearing are also probably involved. Our current knowledge of vocal communication and recognition in this species is sparse. The contact calls of adult females and kids have been suggested to be individually distinct (Lenhardt 1977; Ruiz-Miranda et al. 1993), but have not been examined in detail from a source- filter theory perspective (Fant 1960; Vannoni and McElligott 2007). Furthermore, the few studies on long-range recognition have been performed during the early phase of kids' lives (B2 days) when they hide and not later when they had joined social groups (e.g. Addae et al. 2000).

We analysed calls to examine their coding of individual identity, and assessed the mother-offspring recognition ability using playback experiments in domestic goats. We expected low individuality of kid calls leading to unidirectional recognition of mothers by their kids during the early phase of life when kids are hidden, followed by 
higher individuality and mutual vocal recognition after kids had joined the social group. The aim of this study was to test potential differences in the recognition process that existed between the two phases, rather than measuring the exact timing when recognition takes place. Therefore, we first tested the individuality of calls and the vocal recognition at the end of the hiding phase for domestic goats, at 1-week postpartum. Testing goats at 1week postpartum ensured that mothers and kids had had the opportunity and the time to learn each others' calls before the tests. They were then tested at 5-weeks postpartum, when kids were in their social groups.

\section{Methods}

\section{Subjects and management conditions}

The study was carried out at White Post Farm, Nottinghamshire (53060 N, $1030 \mathrm{~W})$, UK, on four groups consisting of multiparous Pygmy goat mothers $(n=12$; mean \pm SE group size $=3.3 \pm 0.3)$ and their kids $(n=23 ; 5$ females and 18 males; mean \pm SE group size $=5.8 \pm 0.5$ kids). The different kid groups were born in July 2009, December 2009, March 2010 and July 2010, respectively. All kids had the same father and consisted of four single born, eight pairs of twins and one set of triplets.

The goats used in this study were kept indoors in a communal pen of $4.494 .5 \mathrm{~m}$. When a female was about to give birth, she was isolated in a $2.5 \mathrm{~m} 2$ pen within the communal pen and kept there with her kid(s) for 2-3 days to allow adequate development of the mother-offspring relationship (i.e. they were physically isolated but could still hear, see and smell other goats). Mothers and kids were then released in the communal pen with the other goats (hereafter called 'familiar' individuals). During the first week after birth, kids often stayed with siblings next to fences or behind objects provided within the communal pen (e.g. boxes) and away from their mothers, thus displaying typical 'hiding' behaviour (EB and AGM personal observations; see ESM 1 Fig. 1A, B and C). Male kids were castrated by using a constrictive rubber ring applied to the neck of the scrotum 3-4 days after birth (usual procedure in UK). This was carried out as part of routine management of the animals by the owners. Early castration causes a lower growth rate than for intact male kids, but higher than for female kids (Louca et al. 1977), suggesting a role of prenatal testosterone on development in castrated males (Wolf et al. 2002).

\section{Recordings and selection of calls}

We recorded goat kid and mother contact calls at distances of 1-5 $\mathrm{m}$ from the vocalising animal using a Sennheiser MKH70 directional microphone, connected to a Marantz PMD660 numeric recorder (sampling rate: $44.1 \mathrm{kHz}$ ) between $10 \mathrm{am}$ and $5 \mathrm{pm}$. Goat kid contact calls were recorded for the acoustic analysis and the preparation of call sequences used in playback experiments at approximately 1 week postpartum (between 5 and 9 days old for each kid, hereafter ' $1 W$ ' kids) and at approximately 5 weeks postpartum (between 34 and 39 days old for each kid, hereafter ' $5 \mathrm{~W}$ ' kids). This was done by isolating them alone or with their sibling(s) for not more than $5 \mathrm{~min}$ two to three times each day at hearing and visual range from their mothers $(1-10 \mathrm{~m})$. Mothers were recorded at 1-week postpartum during one to three different days, when their kids were kept at 1-10 $\mathrm{m}$ from them. Vocalisations were then imported into a computer at a sampling rate of $44.1 \mathrm{kHz}$ and saved in WAV format at 16-bit amplitude resolution. We used Goldwave v.5.11 (Craig 2000), Praat v.5.0.47 DSP Package (Boersma and Weenink 2009) and Seewave (Sueur et al. 2008) for subsequent analyses and for the preparation of call sequences played back. Calls were visualised on spectrograms in Praat (FFT method, window length $=0.01 \mathrm{~s}$, time steps $=1,000$, frequency steps $=250$, Gaussian window shape, dynamic range $=50 \mathrm{~dB}$ ). Vocalisations with high levels of background noise (as visualised on the spectrogram) were not considered for call analysis or playback experiments. Goats produce closed-mouth contact calls when they are close to each other and openmouth contact calls at greater distance (Ruiz-Miranda et al. 1993). Because our playback experiments mimicked the presence of an individual situated five metres from the tested subjects, only contact calls emitted with the mouth open were used in this study. 


\section{Call analysis}

Acoustic analysis

One mother could not be included in the acoustic analysis because only closed-mouth contact calls could be recorded (total: $n=11$ mothers and 23 kids). To assess the individuality of calls, we selected eight good quality calls per kid at both $5.0 \pm 0.00(1 \mathrm{~W})$ and $36.0 \pm 0.3(5 \mathrm{~W})$ days old (total: 184 calls for each age from 23 kids) and eight good quality calls per mother (total: 88 calls from 11 mothers) for subsequent analyses. The selected calls were separated by at least three calls within a given bout, because consecutive ones are more likely to be homogeneous (Reby et al. 1999). Goat calls are short, with a clear harmonic structure and strong frequency and amplitude modulations (Fig. 1). According to the source-filter theory of voice production (Fant 1960), mammal vocalisations are generated by vibrations of the vocal folds (source, determining the fundamental 'F0') and are subsequently filtered by the supralaryngeal vocal tract (filter, producing amplified frequencies called 'formants', Titze 1994). We extracted source-related vocal features (F0), filter-related acoustic vocal features (formants) as well as intensity measures ( 26 parameters for $1 \mathrm{~W}$ kid calls and 32 parameters for $5 \mathrm{~W}$ kid and mother calls), potentially contributing to vocal distinctiveness (Taylor and Reby 2010), using a custom built programme in Praat. This programme batch processed the editing, the setting of parameters, the analyses and the exporting of output data (Reby and McComb 2003). The vocal parameters that we measured are listed in Table 1 and detailed in ESM 2.
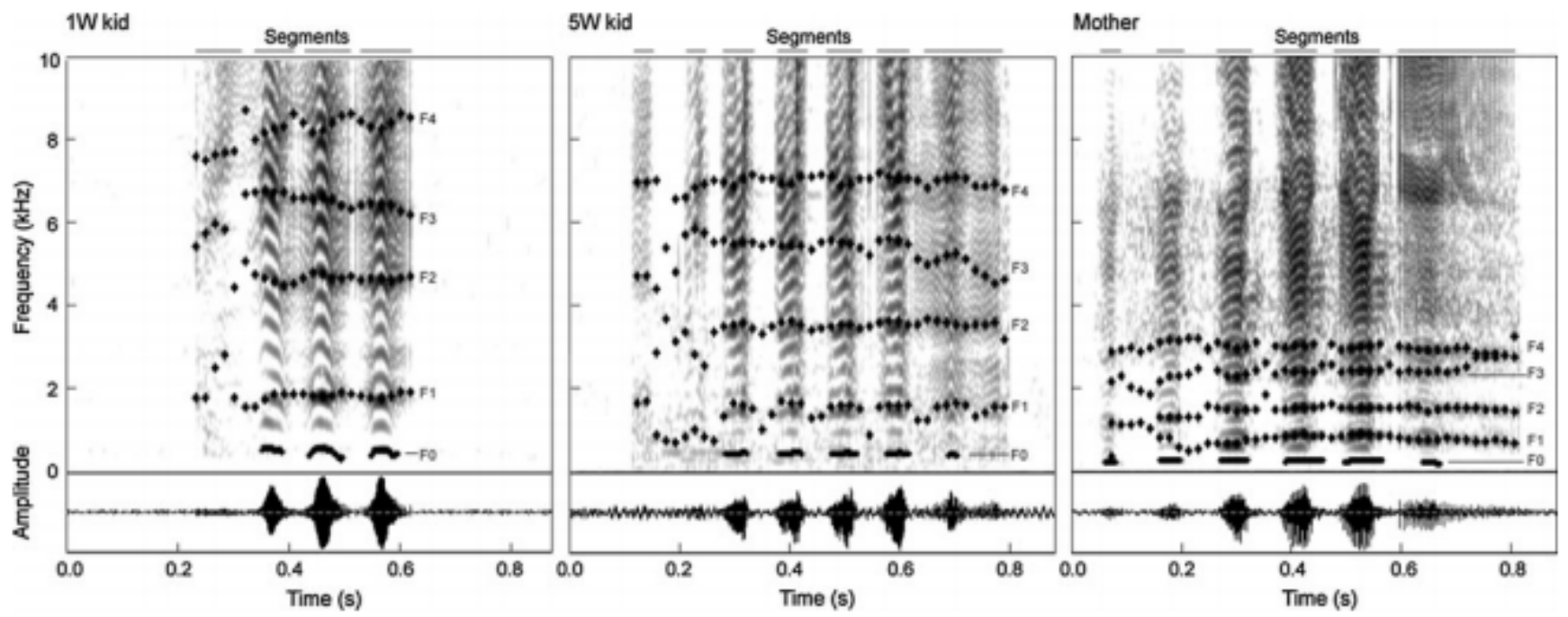

Fig. 1 Spectrograms (above) and oscillograms (below) of one call produced by a $1 \mathrm{~W}$ female kid (left), one call produced by the same female kid at 5W (middle) and one call produced by a mother (right). The black line at the bottom indicates the fundamental frequency contour (F0) and black dots above indicate the frequency values of the first four formants (F1-4). Calls are composed of small acoustic units ('segments'), which are indicated above the spectrograms. Only formant values of the segments were kept for the analyses

\section{Statistical analysis}

First, to investigate individual consistency of changes between $1 \mathrm{~W}$ and $5 \mathrm{~W}$ kid calls, we calculated Kendall rank correlations ('Kendall's tau') between mean values per kid for each vocal parameter measured at $1 \mathrm{~W}$ and 5W. Kendall's tau statistic (values: 0-1) describes the similarity of the orderings of individual kid measures between $1 \mathrm{~W}$ and 5W (consistency of individual differences). We then quantified the individual distinctiveness of mother and kid contact calls by calculating coefficients of variation (CVs) and by performing a principal components analysis (PCA), followed by a multivariate analysis of variance (MANOVA) and a discriminant function analysis (DFA). Calls of kids at $1 \mathrm{~W}, 5 \mathrm{~W}$ kid calls and mother calls were treated separately. 
We computed between and within individual coefficients of variation ( $C V b$ and $C V w$, respectively) as follows: CV $=100 \times(1+1 /(4 \times n)) \times(\mathrm{SD} / \mathrm{Xmean})$, where SD is the standard deviation, Xmean is the mean of the sample and $n$ is the sample size (Sokal and Rohlf 1995). We then calculated a potential of individual coding (PIC) for each parameter with the ratio $\mathrm{CVb} /$ mean $\mathrm{CVw}$, where mean $\mathrm{CVw}$ is the mean value of the $\mathrm{CVw}$ of all individuals. For a given parameter, a PIC value greater than 1 indicates that this parameter is likely to be used for individual recognition because its intra-individual variability is smaller than in inter-individual variability (Robisson et al. 1993). We used a PCA to eliminate redundancy due to the high intercorrelation of the vocal parameters measured and to examine clustering among parameters. Missing data, occurring when one vocal parameter in a given call could not be measured, were replaced by the average value of this parameter for the given individual (percentage of missing data: $1 \mathrm{~W}$ kids, $0.17 \%$ of the values; $5 \mathrm{~W}$ kids, $0.83 \%$ of the values; mothers, $0.79 \%$ of the values). For each category (1W kids, $5 \mathrm{~W}$ kids and mothers), data were confirmed for normality (Kolmogorov-Smirnov test) and log-transformed when necessary. We retained the principal components (PCs) of the PCA with eigenvalues greater than 1 (Kaiser's criterion). The scores of the retained PCs were confirmed for normality (KolmogorovSmirnov test), log-transformed if necessary and used as input variables in the MANOVA and DFA.

We used a MANOVA, with individual identity of goats as a fixed term, to confirm statistical differences in PC scores across individuals. We then used a DFA with one factor ('individual') to quantify the extent to which individuals can be classified on the basis of their calls and which group of variables (PC) account most for this classification (Johnson and Wichern 1992). On the basis of the discriminant functions of the DFA, each PC score (corresponding to a call) was assigned to the appropriate individual (correct classification) or to another individual (incorrect classification) to calculate the percentage of correct classification (CC). We cross-validated our results by performing a leave-one-out classification (McGarigal et al. 2000). We then calculated the CC due to chance by applying a randomisation procedure. The expected level of correct assignment was averaged from DFAs performed on 1,000 randomised permutations of the data set (McGarigal et al. 2000; Solow 1990).

Conventional DFAs only allow the inclusion of a single factor at a time (e.g. 'individual'), and analysing factorial data using such DFA may give incorrect results. The results could indicate a significant discriminability of classes even if they do not differ (Mundry and Sommer 2007). Thus, because our DFAs on $1 \mathrm{~W}$ and $5 \mathrm{~W}$ kid calls included both males and females and individuals of different genetic relatedness levels (full or half siblings), we carried out two additional DFAs to remove the effects of these potentially confounding variables (sex and kinship). For each category (1W and 5W kids), we carried out an additional DFA including only one male kid per mother $(n=11)$ and another DFA including only one female kid per mother $(n=4)$. We then calculated CCs for these DFAs as described above. CC of $1 \mathrm{~W}$ and $5 \mathrm{~W}$ kids were compared using two-tailed paired exact permutation tests.

\section{Playback experiment}

\section{Signals tested}

We tested each goat kid and mother at two periods; at $1 \mathrm{~W}$ (7.41 \pm 0.15 days) and at $5 \mathrm{~W}$ (37.18 \pm 0.30 days), and with two treatments; own mother/own kid and familiar mother/familiar kid, respectively. The familiar individual was an individual from the same group, kept in the communal home pen. Kids and mothers were thus familiar with the calls of this individual. Each treatment consisted of a $30 \mathrm{~s}$ sequence of contact calls interspaced by natural silence intervals measured when mother and kid were separated (mean \pm SE inter-call silence duration: $1 \mathrm{~W}$ kids $=0.73 \pm$ $0.03 \mathrm{~s} ; 5 \mathrm{~W}$ kids $=1.31 \pm 0.09 \mathrm{~s}$; mothers $=0.98 \pm 0.06 \mathrm{~s}$ ). Sequences consisted of at least $50 \%$ of different calls. Each call was never repeated more than three times and never inserted consecutively in the sequence. All calls in a given sequence were rescaled to the same maximum amplitude. To avoid pseudo replication (McGregor 1992), twins and triplets were tested with different sequences of own mother calls and with sequences of calls produced by different familiar females, or at least, with different sequences of calls produced by the same familiar female. Each kid was also tested with different sequences for each treatment between $1 \mathrm{~W}$ and $5 \mathrm{~W}$. Mothers were tested at $1 \mathrm{~W}$ and $5 \mathrm{~W}$ with a sequence of calls of their own kid (or one of their own kids if they had more than one) recorded between 1 and 2 days before the experiment. The familiar kid treatment was a sequence of calls produced by a familiar kid of the same age as their own kid ( \pm 3 days at $1 \mathrm{~W}$ and \pm 5 days at $5 \mathrm{~W}$ ). 
Table 1 Abbreviations for the vocal parameters

\begin{tabular}{|c|c|}
\hline Abbreviation & Parameter \\
\hline F0Start (Hz) & Frequency value of $\mathrm{FO}$ at the start of the call \\
\hline FOEnd $(\mathrm{Hz})$ & Frequency value of $\mathrm{F} 0$ at the end of the call \\
\hline FOMean $(\mathrm{Hz})$ & Mean F0 frequency value across the call \\
\hline FOMin $(\mathrm{Hz})$ & Minimum F0 frequency value across the call \\
\hline FOMax $(\mathrm{Hz})$ & Maximum F0 frequency value across the call \\
\hline TimeFOMax (\%) & Percentage of the total call duration when $\mathrm{F} 0$ is maximum \\
\hline F0AbsSlope (Hz/s) & F0 mean absolute slope \\
\hline FOVar (Hz/s) & Cumulative variation in the F0 contour in Hertz divided by call duration \\
\hline FMRate $\left(s^{-1}\right)$ & Number of complete cycles of F0 modulation per second \\
\hline FMExtent $(\mathrm{Hz})$ & Mean peak-to-peak variation of each F0 modulation \\
\hline Jitter (\%) & Mean absolute difference between frequencies of consecutive F0 periods divided by the mean frequency of F0 \\
\hline Shimmer (\%) & Mean absolute difference between the amplitudes of consecutive F0 periods divided by the mean amplitude of F0 \\
\hline F1Mean $(\mathrm{Hz})$ & Mean frequency value of the first formant \\
\hline F2Mean $(\mathrm{Hz})$ & Mean frequency value of the second formant \\
\hline F3Mean $(\mathrm{Hz})$ & Mean frequency value of the third formant \\
\hline F4Mean $(\mathrm{Hz})$ & Mean frequency value of the fourth formant \\
\hline F1Min $(\mathrm{Hz})$ & Minimum frequency value of the first formant \\
\hline F2Min $(\mathrm{Hz})$ & Minimum frequency value of the second formant \\
\hline F3Min $(\mathrm{Hz})$ & Minimum frequency value of the third formant \\
\hline F4Min $(\mathrm{Hz})$ & Minimum frequency value of the fourth formant \\
\hline $\mathrm{F} 1 \mathrm{Max}(\mathrm{Hz})$ & Maximum frequency value of the first formant \\
\hline $\mathrm{F} 2 \mathrm{Max}(\mathrm{Hz})$ & Maximum frequency value of the second formant \\
\hline F3Max $(\mathrm{Hz})$ & Maximum frequency value of the third formant \\
\hline $\mathrm{F} 4 \mathrm{Max}(\mathrm{Hz})$ & Maximum frequency value of the fourth formant \\
\hline DfMin $(\mathrm{Hz})$ & Minimum spacing of the formants \\
\hline MaxVTL (cm) & Estimated maximum vocal tract length \\
\hline Q25\% (Hz) & Frequency value at the upper limit of the first quartiles of energy \\
\hline Q50\% (Hz) & Frequency value at the upper limit of the first quartiles of energy \\
\hline Q75\% (Hz) & Frequency value at the upper limit of the third quartiles of energy \\
\hline AmpVar (dB/s) & Cumulative variation in amplitude divided by the total call duration \\
\hline AMRate $\left(\mathrm{s}^{-1}\right)$ & Number of complete cycles of amplitude modulation per second \\
\hline AMExtent $(\mathrm{dB})$ & Mean peak-to-peak variation of each amplitude modulation \\
\hline Dur (s) & Duration of the call \\
\hline
\end{tabular}

Short description of the vocal parameters measured (see ESM 2 for more details)

\section{Playback procedure}

We played back call sequences, stored as mp3 files on an SD card at a sampling rate of $44.1 \mathrm{kHz}$ and a bit rate of $224 \mathrm{kbps}$, using a Skytronic TEC076 portable system (frequency response: $50-20 \mathrm{kHz} \pm 3 \mathrm{~dB}$ ). Mothers were tested in their home pen when their own kid(s) had been removed and isolated at non-visual and non-hearing range from them. Kids were tested individually in a $2.5 \mathrm{~m}^{2}$ arena situated at non-hearing and non-visual range from the home pen, where their mothers remained. Furthermore, one observer checked whether mothers were silent when kids were tested, and vice versa. The loudspeaker was situated at 4-6 $\mathrm{m}$ from the test arena for kids 
or 4-6 $\mathrm{m}$ from the mothers at the beginning of the playback, hidden behind a fence. We played back signals at the intensity estimated to be normal for the goats (mean \pm SE: kid call sequences $=81.19 \pm 1.51 \mathrm{~dB}$; mother call sequences $=79.76 \pm 1.27 \mathrm{~dB}$ measured at $1 \mathrm{~m}$ using an ASL-8851 sound level metre, linear setting). Because of an important order effect detected for kids during preliminary experiments at both $1 \mathrm{~W}$ and $5 \mathrm{~W}$ when they were tested with the two treatments (own and familiar) on the same day (reaction only to the first treatment and never to the second one, independently of the treatment), kids were tested on two consecutive days with one treatment per day. Mothers were tested with the two treatments (own and familiar) on the same day, with a 5-10 min interval that allowed them to return to a normal activity or on consecutive days when they did not return to a normal activity (e.g. feeding) after this time interval (8 out of 21 cases). For both mothers and kids, the two treatments were presented in a random order.

Because of the hiding tendency of kids at $1 \mathrm{~W}$, they only responded to playbacks after being prevented from suckling for at least $1.5 \mathrm{~h}$ (EB and AGM personal observations, see also Addae et al. 2000). Such separation lengths are normal when kids sleep away from their mothers (up to $5 \mathrm{~h}$ during the first week postpartum, Lickliter 1984). We thus isolated the kids in groups (2-4 kids together) in the playback arena during 1.5-2 $\mathrm{h}$ after a suckling event and prior to the tests, which also allowed the kids to get habituated to the playback arena. When the first kid was tested with the playback experiment, the other kids were moved to another arena of the same size at non-visual and non-hearing range. They were returned to their mothers directly after being tested (maximum after $2.5 \mathrm{~h}$ of isolation). Kids were never left alone except during the playback experiments (3-4 min). At $5 \mathrm{~W}$, we did not need to isolate the kids prior to the tests to obtain a response. They were only isolated in groups in the playback arena or an arena of similar size for 10-15 min when their mothers were being tested. The playback started when subjects were settled (2-3 min after being released in the playback arena). To account for between-day and between-individual differences in reaction to isolation, pre-treatment behaviour was scored $20 \mathrm{~s}$ before the beginning of the experiment and included in our analyses. The observer stood at 5-10 $\mathrm{m}$ from the tested animal and video recorded the tests for further analyses using a Sony DCR-SX50E camcorder. Kids that experienced stress during the playbacks were not tested. Therefore, in total, at $1 \mathrm{~W}$, twenty-two kids were tested with both treatments. At $5 \mathrm{~W}$, nineteen kids were tested with both treatments and one kid with the familiar treatment only. One mother could not be tested at $5 \mathrm{~W}$ because her kid could not be isolated (i.e. in total, 11 mothers were tested at $1 \mathrm{~W}$ and 10 mothers at $5 \mathrm{~W}$ ).

\section{Responses measured}

The behavioural responses of the goats to the various treatments were assessed from videos of the playbacks using CowLog 1.1 (Hänninen and Pastell 2009). We scored the responses during $20 \mathrm{~s}$ of pre-playback observation and $30 \mathrm{~s}$ of playback observation (50 s of observation in total). During the pre-playback observation, we measured the number of calls produced and the duration of movements (preDurMov). The number of calls produced was then divided by the total duration (30 s) to obtain the pre-playback rate of calling (preRateCall). During the playback, we scored the number of calls produced, the duration of movements (DurMov), the duration of looks towards the loudspeaker (DurLooks) and the latency to react (LatReac), i.e., to call, move or look towards the loudspeaker. Individuals were considered as looking towards the loudspeaker when their head was orientated in the direction of the loudspeaker with their ears orientated forward. The number of calls produced was then divided by the total duration ( $30 \mathrm{~s}$ ) to obtain the rate of calling in response to the playback (RateCall).

\section{Statistical analyses}

We tested for differences across periods $(1 \mathrm{~W} / 5 \mathrm{~W})$ and across treatments (Own/Familiar) using generalised linear mixed models (GLMMs) fitted by maximum likelihood (glmmPQL function in R), which allowed us to include several factors potentially affecting goat responses (pre-playback measures, treatment order, individual identity, mother identity and sex of the kids), and which handle non-normal data by using exponential family distributions and link functions (Bolker et al. 2009). Each response measure (dependent variable) was treated separately. In each model, we included as a fixed effect, the treatment (Own/Familiar to assess Own vs. Familiar treatment differences at $1 \mathrm{~W}$ and at $5 \mathrm{~W}$; or $1 \mathrm{~W} / 5 \mathrm{~W}$ to assess $1 \mathrm{~W}$ vs. $5 \mathrm{~W}$ differences in response to Own and Familiar 
treatments). We included as covariates, the treatment order to correct for potential order effects and preplayback measures for DurMov (i.e. preDurMov) and RateCall (i.e. preRateCall). In the models assessing kid responses, the sex of the kids was also included as a fixed effect, to control for sex differences. We included as a random effect, the individual identity of the kids nested within the individual identity of their mothers to account for individual and kinship (half/full siblings) differences. In the models assessing mother responses, we included as a random effect, the individual identity of the mothers to account for individual differences. Because our data were not normally distributed and not transformable to normality (left-skewed distribution), we fitted the data with a gamma family distribution and either log or inverse link function, depending on the response measures after examination of the residuals of the GLMMs (Q-Q plots).

We carried out statistical analyses using R v.2.9.0 (R Development Core Team 2009). All tests were two-tailed and the significance level was set at $a=0.05$. All means are given with $S E s$.

\section{Results}

\section{Call analysis}

Mean values, Kendall's tau and PIC values of the vocal parameters obtained for $1 \mathrm{~W}$ kid, $5 \mathrm{~W}$ kid and mother calls are shown in Table 2. All parameter means were lower for mothers than for $5 \mathrm{~W}$ kids, and lower for $5 \mathrm{~W}$ kids than for $1 \mathrm{~W}$ kids, except Dur and MaxVTL, which showed the opposite effect (i.e. mothers[5W kids[1W kids). Other parameters (TimeFOMax, Jitter, Shimmer) were constant across categories of individuals, and Q25\% was slightly higher for $5 \mathrm{~W}$ kids than $1 \mathrm{~W}$ kids (Table 2). Estimated MaxVTL were of $7.9 \mathrm{~cm}$ for $1 \mathrm{~W}$ kids, $9.1 \mathrm{~cm}$ for $5 \mathrm{~W}$ kids and $21.3 \mathrm{~cm}$ for mothers. These values were highly correlated with the observed measures of kid and mother head lengths (Spearman rank correlation: $n=29$ values, $r=0.81, p<0.0001$ ).

PIC values greater than 1 indicate parameters for which the intra-individual variability $(C V w)$ is smaller than the inter-individual variability (CVb), i.e., parameters that are individualised and thus potentially used for individual recognition. All parameters linked to the F0-contour had PIC values greater than 1, especially FOMean, which had a PIC value of 3.3 for mother calls. Most filter-related features had PIC values greater than 1 for $1 \mathrm{~W}$ kids and mothers, but not for 5W kids (except F1Mean), where PIC values ranged from 0.62 (F3Min) to 0.99 (F4Mean). FMExtent (mothers), Jitter (5W kids and mothers), AmpVar (5W kids) and AMExtent (5W kids and mothers) also had PIC values greater than 1 (Table 2). Several vocal parameters showed consistent individual differences between $1 \mathrm{~W}$ and $5 \mathrm{~W}$ kid calls (significant Kendall's tau). Spectrum-related parameters, especially Q25\% and Q50\%, showed high Kendall's tau (>0.5), indicating high individual consistency of changes (Table 2).

The PCAs generated 6 PCs for $1 \mathrm{~W}$ kids ( $n=184$ calls, 23 kids, 26 vocal parameters), 9 PCs for $5 \mathrm{~W}$ kids $(n=184$ calls, 23 kids, 32 vocal parameters) and 8 PCs for mothers ( $n=88$ calls, 11 females, 32 vocal parameters) that exceeded Kaiser's criterion (eigenvalues $>1$ ), and whose scores were consequently used as input variables in the MANOVAs and DFAs. These components combined accounted for $83.2 \pm 1.1 \%$ of the variation in the original data sets. For each category (1W kids, $5 \mathrm{~W}$ kids and mothers), filter-related parameters (formants and energy quartiles (Q25\%, Q50\% and Q75\%) for 1W kids and adults females) were grouped in PC1 and source-related parameters (F0 contour and Jitter for mothers) were grouped in PC2. The vocal parameters correlated with the other PCs varied between $1 \mathrm{~W}$ kids, 5W kids and mothers (see ESM 3 Table 1A, B and C for more details on the factor loadings of the vocal parameters on the principal components).

There were significant differences among $1 \mathrm{~W}$ kids, $5 \mathrm{~W}$ kids and mothers in PC scores (MANOVA: 1W kids, $F_{132,966}=7.56, p<0.0001 ; 5 \mathrm{~W}$ kids, $F_{198,1449}=5.85, p<0.0001 ;$ mothers, $\left.F_{80,616}=6.11, P<0.0001\right)$. For each category of individuals, DF1 and/or DF2 were highly correlated with either PC1 (formants and energy quartiles) or PC2 (F0 contour) or with both PCs. For $1 \mathrm{~W}$ males, DF2 was not highly correlated with PC1 or PC2 $(r>0.50)$, but with PC3 (F1 and F4-related measures and DfMin). For 1W females, DF1 and DF2 were also highly correlated with PC3 (F1 and F4-related measures and DfMin), PC4 (Q50\% and Q75\%) and PC6 (Jitter). For 5W kids, DF2 was highly correlated with PC3 (energy quartiles, Shimmer and all AM-related measures) and PC6 (F1Max). For 
5W males, DF2 was highly correlated with PC3 (energy quartiles, Shimmer and all AM-related measures). For 5W females, DF1 was also highly correlated with PC4 (F0AbsSlope, F0Var and FMExtent) and PC5 (F1Min and F1Mean; see ESM 3 Table 2A, B and C for more details on the correlations between $1 \mathrm{~W}$ kid, $5 \mathrm{~W}$ kid and mother PC scores and discriminant functions generated by the DFAs).

Table 2 Mean values, PIC values and Kendall's tau of the vocal parameters obtained for $1 \mathrm{~W}$ kid, $5 \mathrm{~W}$ kid and mother calls (mean \pm SE)

\begin{tabular}{|c|c|c|c|c|c|c|c|c|c|c|}
\hline \multirow[t]{2}{*}{ Parameter } & \multicolumn{3}{|l|}{ 1W kids } & \multicolumn{3}{|l|}{$5 W$ kids } & \multirow{2}{*}{$\begin{array}{l}\text { Kendall's tau } \\
1 W-5 W\end{array}$} & \multicolumn{3}{|l|}{ Mothers } \\
\hline & Mean & SE & PIC & Mean & SE & PIC & & Mean & SE & PIC \\
\hline F0Start (Hz) & 574.8 & 8.6 & 1.47 & 537.1 & 4.6 & 1.18 & $0.39 *$ & 212.3 & 9.7 & 2.26 \\
\hline F0End $(\mathrm{Hz})$ & 568.4 & 7.1 & 1.38 & 507.7 & 4.3 & 1.05 & 0.21 & 213.1 & 7.6 & 1.31 \\
\hline FOMean $(\mathrm{Hz})$ & 587.6 & 6.8 & 1.68 & 545.1 & 3.8 & 1.64 & $0.40^{* *}$ & 223.0 & 9.0 & 3.33 \\
\hline FOMin $(\mathrm{Hz})$ & 538.1 & 7.6 & 1.46 & 492.7 & 4.2 & 1.15 & 0.29 & 187.0 & 8.2 & 1.98 \\
\hline F0Max $(\mathrm{Hz})$ & 621.1 & 7.0 & 1.75 & 572.8 & 3.8 & 1.59 & $0.42^{* *}$ & 252.0 & 9.1 & 2.46 \\
\hline TimeFOMax (\%) & 42.6 & 2.0 & 0.42 & 38.5 & 1.8 & 0.50 & 0.19 & 46.7 & 3.3 & 0.71 \\
\hline F0AbsSlope (Hz/s) & 572.0 & 27.5 & 0.75 & 322.5 & 11.6 & 0.87 & 0.12 & 221.9 & 20.3 & 1.00 \\
\hline FOVar $(\mathrm{Hz} / \mathrm{s})$ & $\mathrm{N} / \mathrm{A}$ & $\mathrm{N} / \mathrm{A}$ & N/A & 227.4 & 8.6 & 0.63 & N/A & 141.6 & 14.9 & 0.61 \\
\hline FMRate $\left(\mathrm{s}^{-1}\right)$ & $N / A$ & $N / A$ & N/A & 4.8 & 0.1 & 0.72 & $N / A$ & 3.7 & 0.2 & 0.93 \\
\hline FMExtent (Hz) & $\mathrm{N} / \mathrm{A}$ & $\mathrm{N} / \mathrm{A}$ & N/A & 56.7 & 3.9 & 0.69 & N/A & 48.6 & 6.8 & 1.14 \\
\hline Jitter (\%) & 4.3 & 0.2 & 0.78 & 3.7 & 0.1 & 1.27 & 0.14 & 5.5 & 0.3 & 1.43 \\
\hline Shimmer (\%) & 17.6 & 0.4 & 0.75 & 17.2 & 0.3 & 0.91 & $0.31^{*}$ & 18.1 & 0.6 & 0.65 \\
\hline F1Mean $(\mathrm{Hz})$ & 1789.9 & 32.6 & 1.10 & 1691.4 & 15.0 & 1.01 & 0.23 & 848.8 & 9.0 & 0.68 \\
\hline F2Mean $(\mathrm{Hz})$ & 4100.3 & 71.5 & 1.32 & 3821.7 & 28.5 & 0.89 & 0.25 & $1,545.3$ & 28.0 & 1.92 \\
\hline F3Mean $(\mathrm{Hz})$ & 6439.3 & 48.8 & 1.21 & 5692.7 & 32.3 & 0.78 & 0.20 & $2,476.6$ & 24.4 & 1.37 \\
\hline F4Mean $(\mathrm{Hz})$ & 8554.9 & 50.0 & 1.14 & 7514.7 & 41.0 & 0.99 & $0.30 *$ & $3,302.3$ & 32.5 & 1.34 \\
\hline F1Min (Hz) & 1397.0 & 34.8 & 0.95 & 1348.8 & 19.5 & 0.69 & $0.30^{*}$ & 697.7 & 14.6 & 0.77 \\
\hline F2Min $(\mathrm{Hz})$ & 3656.6 & 73.4 & 1.12 & 3424.6 & 36.5 & 0.91 & 0.27 & $1,366.2$ & 30.5 & 2.13 \\
\hline F3Min $(\mathrm{Hz})$ & 6033.7 & 52.3 & 1.08 & 5278.4 & 33.7 & 0.62 & 0.09 & $2,315.9$ & 25.1 & 1.24 \\
\hline F4Min $(\mathrm{Hz})$ & 8126.2 & 51.6 & 0.99 & 7068.5 & 43.2 & 0.82 & 0.17 & $3,113.3$ & 34.0 & 1.38 \\
\hline F1Max (Hz) & 2124.8 & 36.7 & 1.00 & 1972.7 & 19.8 & 0.84 & 0.23 & 957.4 & 8.8 & 0.64 \\
\hline F2Max $(\mathrm{Hz})$ & 4526.1 & 70.4 & 1.31 & 4206.1 & 30.5 & 0.75 & 0.26 & $1,724.8$ & 29.6 & 1.31 \\
\hline F3Max (Hz) & 6835.3 & 53.0 & 1.09 & 6161.6 & 39.9 & 0.73 & 0.23 & $2,649.0$ & 25.9 & 1.10 \\
\hline F4Max $(\mathrm{Hz})$ & 9038.3 & 57.0 & 1.09 & 8019.1 & 47.9 & 0.92 & $0.42^{\star *}$ & $3,504.7$ & 33.2 & 1.10 \\
\hline DfMin $(\mathrm{Hz})$ & 2265.5 & 21.1 & 1.07 & 1933.5 & 12.5 & 0.82 & 0.24 & 829.2 & 9.3 & 1.00 \\
\hline MaxVTL (cm) & 7.9 & 0.1 & N/A & 9.1 & 0.1 & $\mathrm{~N} / \mathrm{A}$ & N/A & 21.3 & 0.2 & N/A \\
\hline Q25\% (Hz) & 1215.3 & 73.3 & 1.24 & 1302.4 & 46.8 & 0.90 & $0.57^{\star \star *}$ & 825.3 & 36.0 & 0.92 \\
\hline Q50\% (Hz) & 3002.2 & 122.8 & 1.19 & 2823.2 & 85.7 & 0.94 & $0.53^{\star * *}$ & $1,951.3$ & 79.7 & 1.36 \\
\hline Q75\% (Hz) & 6019.4 & 152.3 & 1.27 & 5196.9 & 105.5 & 0.84 & $0.34^{* *}$ & $3,691.3$ & 101.3 & 1.07 \\
\hline AmpVar (dB/s) & $\mathrm{N} / \mathrm{A}$ & $\mathrm{N} / \mathrm{A}$ & N/A & 202.4 & 5.8 & 1.01 & N/A & 143.1 & 6.6 & 1.00 \\
\hline AMRate $\left(s^{-1}\right)$ & $\mathrm{N} / \mathrm{A}$ & $\mathrm{N} / \mathrm{A}$ & N/A & 11.6 & 0.2 & 0.79 & N/A & 8.1 & 0.2 & 0.67 \\
\hline AMExtent $(\mathrm{dB})$ & $\mathrm{N} / \mathrm{A}$ & $\mathrm{N} / \mathrm{A}$ & N/A & 19.4 & 0.7 & 1.06 & N/A & 18.7 & 1.0 & 1.01 \\
\hline Dur (s) & 0.3 & 0.0 & 0.72 & 0.6 & 0.0 & 0.86 & --0.03 & 0.7 & 0.0 & 0.56 \\
\hline
\end{tabular}

Results of Kendall's tau between $1 \mathrm{~W}$ and $5 \mathrm{~W}$ kid measures are indicated as follows: ${ }^{*} \mathrm{p}<0.05,{ }^{* *} \mathrm{p}<0.01,{ }^{\star \star *} \mathrm{p}<0.001$. Bold types indicate significant Kendall's tau and PIC values $>1$. See Table 1 for abbreviations of the vocal parameters 
Cross-validated DFAs correctly classified $53.47 \pm 5.13 \%$ of $1 \mathrm{~W}$ kid calls, $54.86 \pm 4.65 \%$ of $5 \mathrm{~W}$ kid calls (1W and $5 \mathrm{~W}: \mathrm{n}=23$, chance level $=4.34 \pm 0.05 \%)$ and $69.32 \pm 5.68 \%$ of mother calls $(n=11$, chance level $=9.00 \pm$ $0.10 \%$, Fig. 2). Cross-validated DFAs carried out on male or female kid calls only (one individual per mother) correctly classified $52.27 \pm 8.89 \%$ of $1 \mathrm{~W}$ male calls, $68.18 \pm 7.02 \%$ of $5 \mathrm{~W}$ male calls ( $1 \mathrm{~W}$ and $5 \mathrm{~W}: \mathrm{n}=11$, chance level $=9.09 \pm 0.11 \%$, Fig. 2 ), $87.50 \pm 5.10 \%$ of $1 \mathrm{~W}$ female calls and $90.63 \pm 5.98 \%$ of $5 \mathrm{~W}$ female calls ( $1 \mathrm{~W}$ and $5 \mathrm{~W}: \mathrm{n}=4$, chance level $=25.08 \pm 0.25 \%$ ). All these correct classification rates $(\mathrm{CCs})$ were higher than the CCs due to chance (permutation tests: 1,000 permutations, $p=0.0009$ for each comparison). CCs of kid calls calculated at $5 \mathrm{~W}$ were higher than at $1 \mathrm{~W}$ (two-tailed paired exact permutation tests: $\mathrm{n}=15,11$ males and 4 females, $p=0.0001$ ). Thus, both kid and mother contact calls were individualised, and the individual identity of kid calls was more evident at $5 \mathrm{~W}$ than at $1 \mathrm{~W}$.
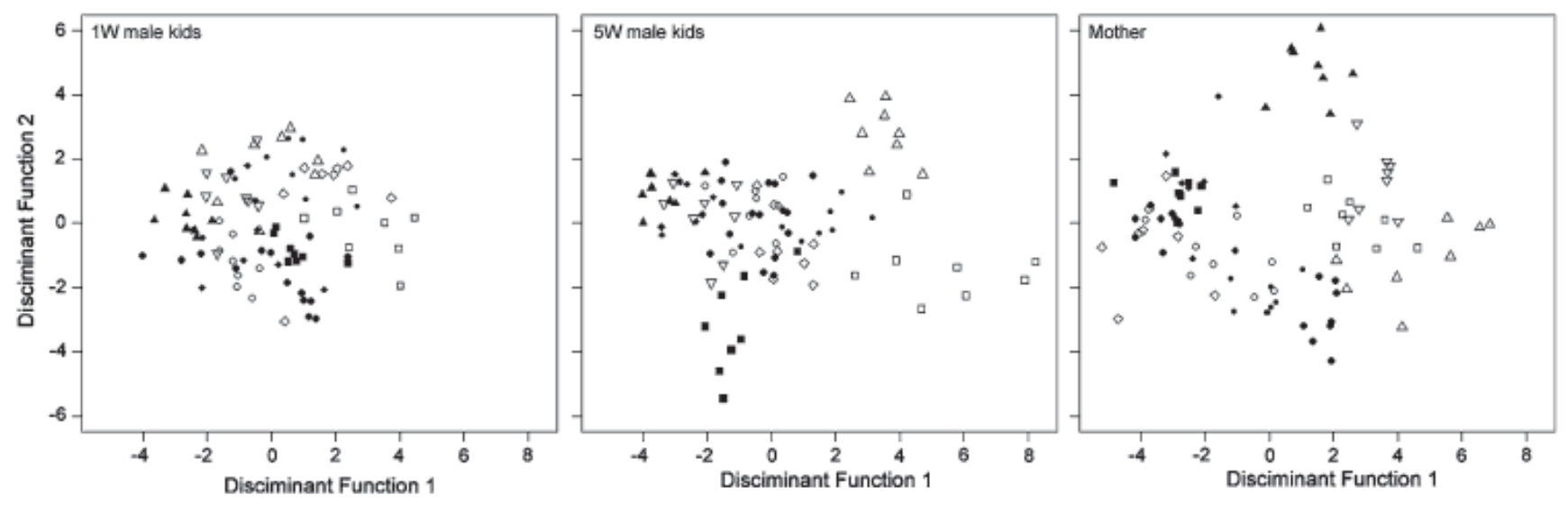

Fig. 2 Discriminant function scores of $1 \mathrm{~W}$ male kid calls (left, one kid per mother, $n=11,8$ calls per individual, correct classification $=52.3 \%$ ), of calls of the same kids at $5 \mathrm{~W}$ (middle, $n=11,8$ calls per individual, correct classification $=68.2 \%$ ) and of their mothers' calls (right, $n=11,8$ calls per individual, correct classification $=69.3 \%$ ). The calls of a given kid at $1 \mathrm{~W}$ and $5 \mathrm{~W}$ and the calls of his mother are indicated with the same shapes. $1 \mathrm{~W}$ kid calls, $5 \mathrm{~W}$ kid calls and mother calls were individualised. $5 \mathrm{~W}$ kid calls were more individualised than calls of the same kids at $1 \mathrm{~W}$ (see results for statistics)

Playback experiment

Kids

At $1 \mathrm{~W}$, kids called more and reacted faster during the own mother's playback treatment (Own) than during the familiar female treatment (Familiar; GLMM, inverse link function: RateCall, t19 $=2.12, p=0.048$, Fig. 3a; LatReac, t20 $=-4.42, p=0.0003$, Fig. 3d). The other response measures did not differ significantly between the Own and Familiar treatments (GLMM, log link function: DurMov, t19 $=-0.98, p=0.34$, Fig. 3b; DurLooks, t20 = $-1.01, p=0.33$, Fig. 3c). At 5W, kids spent more time looking towards the loudspeaker and reacted faster during the Own than during the Familiar treatment (GLMM: DurLooks, t17 $=-2.41, p=0.028$, Fig. 3c; LatReac, $\mathrm{t} 17=$ $-4.68, p=0.0002$, Fig. 3d). The other response measures did not differ significantly between the Own and Familiar treatments (GLMM: RateCall, t16 = 1.28, $\mathrm{p}=0.22$, Fig. 3a; DurMov, t16 $=-1.16, \mathrm{p}=0.26$, Fig. 3b).

Kids spent, though not significantly, more time moving during the Familiar treatment at $1 \mathrm{~W}$ than 5W (GLMM: DurMov, $\mathrm{t} 17=2.03, \mathrm{p}=0.059$, Fig. $3 \mathrm{~b}$ ). The other response measures did not differ significantly between $1 \mathrm{~W}$ and 5W kids for either Own or Familiar treatments (GLMM: RateCall, Own, t16 $=1.50, p=0.15$, Familiar, t17 $=0.24, p$ $=0.81$, Fig. 3a; DurMov, Own, t16 $=-0.48, p=0.64$, Fig. 3b; DurLooks, Own, t17 = -0.48, p = 0.63, Familiar, t18 = 1.11, $p=0.28$, Fig. 3c; LatReac, Own, t17 $=-0.77, p=0.45$, Familiar, t18 $=0.96, p=0.35$, Fig. 3d). Thus, kids responded more to their own mother compared to a familiar female at both $1 \mathrm{~W}$ and $5 \mathrm{~W}$. 


\section{Mothers}

When kids were $1 \mathrm{~W}$, mothers called more, spent more time looking towards the loudspeaker and reacted faster during the own kid's playback treatment (Own) than during the familiar kid treatment (Familiar; GLMM: RateCall, inverse link function, t8 $=5.87, p=0.0004$, Fig. 4a; DurLooks, log link function, t9 $=-3.12, p=0.012$, Fig. 4c; LatReac, log link function, $t 9=3.17, p=0.012$, Fig. 4d). DurMov did not differ significantly between the Own and Familiar treatments (GLMM: log link function, t8 $=-1.81, p=0.11$, Fig. $4 b$ ). When kids were $5 \mathrm{~W}$, mothers called more and spent more time looking towards the loudspeaker during the Own than during the Familiar treatment (GLMM: RateCall, t7 $=3.49, p=0.010$, Fig. 4a; DurLooks, t8 $=-4.42, p=0.002$, Fig. $4 \mathrm{c}$ ). The other response measures did not differ significantly between the Own and Familiar treatments (GLMM: DurMov, t7 $=-0.92, \mathrm{p}=$ 0.39, Fig. 4b; LatReac, t8 $=0.58, p=0.58$, Fig. 4d).

Mothers reacted, though not significantly, faster during the Own treatment at 5W than at $1 \mathrm{~W}$ (GLMM: LatReac, t8 $=-2.27, p=0.053$, Fig. 4d). The other response measures did not differ significantly between $1 \mathrm{~W}$ and $5 \mathrm{~W}$ postpartum for either Own or Familiar treatments (GLMM: RateCall, Own, t7 $=-0.45, \mathrm{p}=0.67$, Familiar, $\mathrm{t} 7=-1.27$, $p=0.24$, Fig. 4a; DurMov, Own, t7 $=1.93, p=0.10$, Familiar, $t 7=0.26, p=0.80$, Fig. 4b; DurLooks, Own, t8 $=$ $0.28, p=0.79$, Familiar, t8 $=-0.82, p=0.43$, Fig. 4c; LatReac, Familiar, t8 $=-0.24, p=0.82$, Fig. 4d). Thus, mothers responded more to their own kids compared to familiar kids at both $1 \mathrm{~W}$ and $5 \mathrm{~W}$.
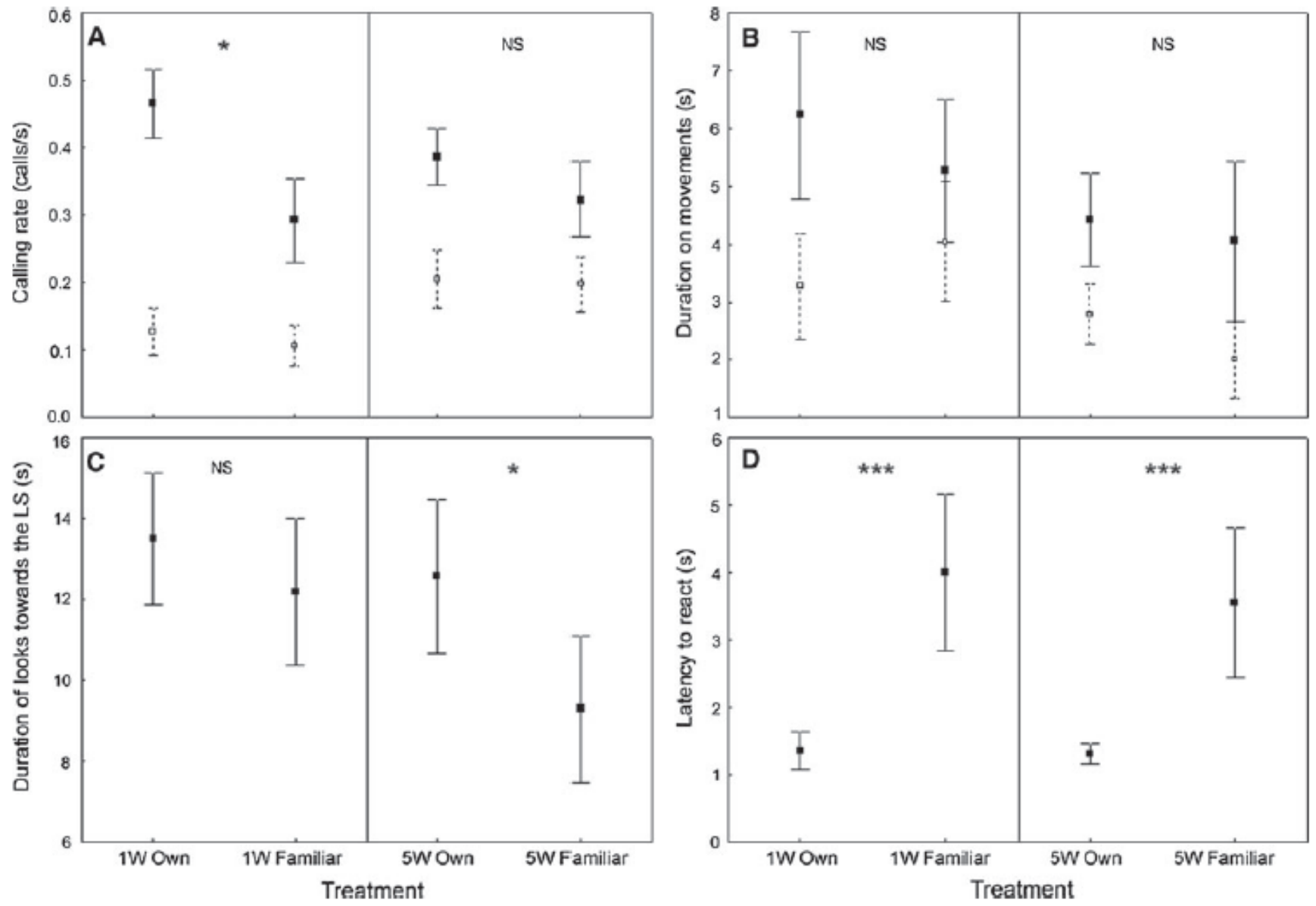

Fig. 3 Kid responses to playbacks at $1 \mathrm{~W}$ and $5 \mathrm{~W}$. a rate of calling; b duration of movements; c duration of looks towards the loudspeaker and $\mathrm{d}$ latency of kids to respond to calls of their own mother (Own) or to a familiar female (Familiar; GLMM, *pl0.05, ${ }^{\star * \star}$ pl0.001, NS $=$ non significant; mean \pm SE). Dashed means \pm SE in (a) and (b) indicate pre-treatment measures. Kids responded more to their own mothers than to familiar females at both $1 \mathrm{~W}$ and $5 \mathrm{~W}$ 


\section{Discussion}

We investigated the hypothesis that the ability of mothers and offspring to vocally recognise each other (unidirectional vs. mutual recognition) is linked to predator avoidance strategies (hider vs. follower) in ungulates. We predicted that goat kids (hider species) would have low call individuality leading to unidirectional recognition of mothers by offspring when kids were still hidden from their mothers most of the time (1-week postpartum, 1W), followed by higher offspring call individuality and mutual recognition after kids have normally joined the social group (5 weeks, 5W). Contrary to our predictions, our acoustic analysis (PIC, MANOVA, DFA) showed that the calls of both mothers and kids were individualised, even for $1 \mathrm{~W}$ kids, potentially providing cues for individual recognition. Filter-related vocal parameters (formants and energy quartiles), and especially source-related vocal parameters (F0 contour, PIC values[1), were the most important cues to individual identity. The calls of kids showed some consistent individual differences between $1 \mathrm{~W}$ and $5 \mathrm{~W}$ and more inter-individual variability at $5 \mathrm{~W}$ than at $1 \mathrm{~W}$. We also found evidence for mutual vocal recognition at both $1 \mathrm{~W}$ and $5 \mathrm{~W}$. We did not observe any significant difference in the responses of mothers and kids to playbacks between the two phases. This suggests that mother-offspring vocal recognition in domestic goats is more similar to that predicted for followers (e.g. sheep, Sèbe et al. 2007) than for hiders (e.g. fallow deer, Torriani et al. 2006). The high vocal individualities we found, along with strong mutual vocal recognition abilities, are the characteristic of species living in large, complex social groups (Miranda-de la Lama and Mattiello 2010; Pollard and Blumstein 2011).
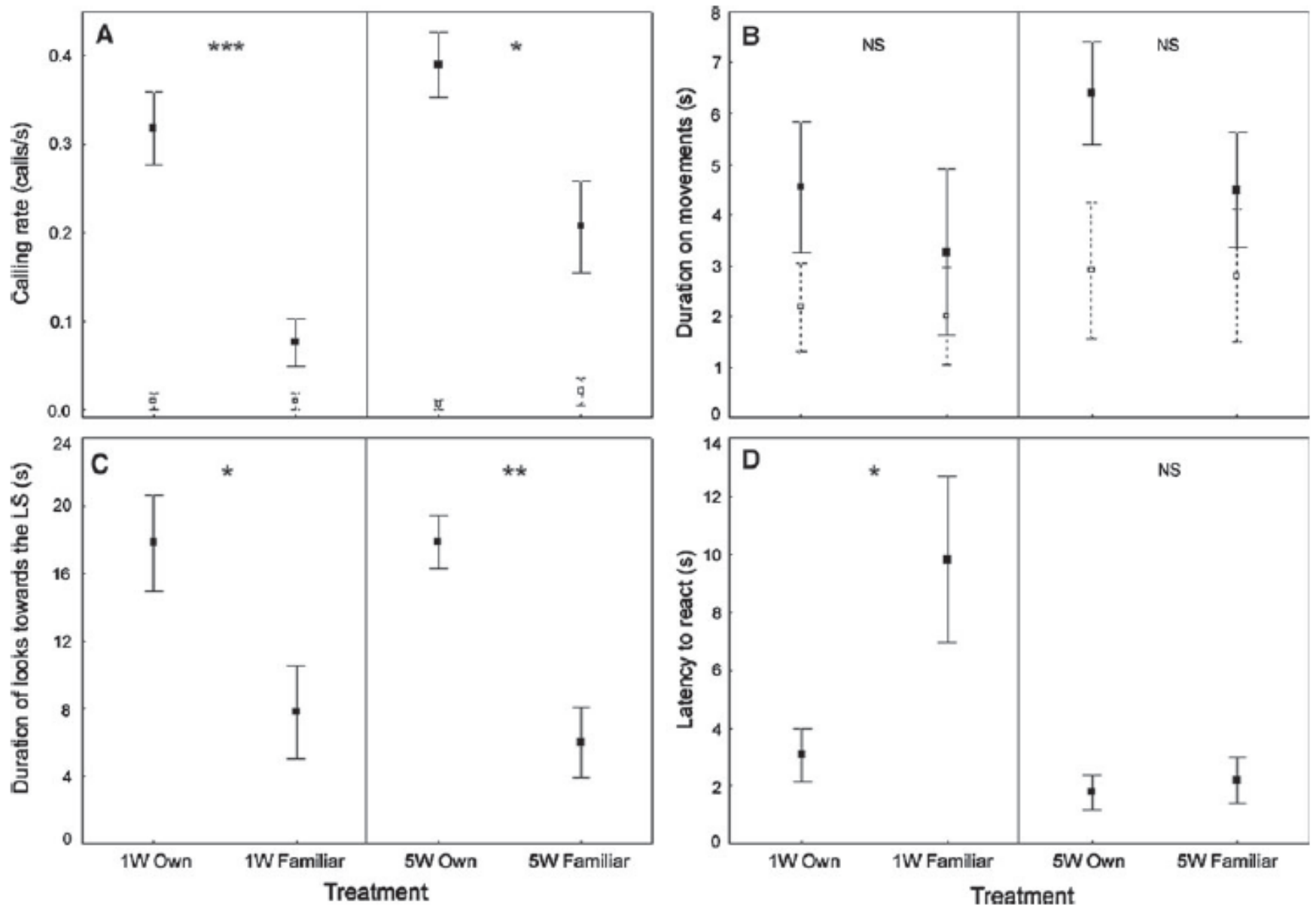

Fig. 4 Mother responses to playbacks at $1 \mathrm{~W}$ and 5W. a Rate of calling; b duration of movements; c duration of looks towards the loudspeaker and d latency of mothers to respond to calls of their own kid (Own) or to a familiar kid of the same age (Familiar; GLMM, *pl0.05, ${ }^{\star *}$ pl0.01, *** pl0.001, NS = non significant; mean \pm SE). Dashed means \pm SE in (a) and (b) indicate pretreatment measures. Mothers responded more to their own kids than to familiar kids at both $1 \mathrm{~W}$ and $5 \mathrm{~W}$ 
Our results provide evidence for offspring call individuality and mother-offspring mutual vocal recognition in a hider species, even during the hiding phase. These results contrast with the only other hider species in which low individuality of offspring call and unidirectional recognition of mothers by offspring have been shown (fallow deer, Torriani et al. 2006). The differences observed between goats and fallow deer could be because fallow deer are under lower selection pressure than goats for individual recognition of offspring by mothers, and thus for offspring call individuality. Fallow deer fawns hide during their first 3 weeks of life. During this hiding phase, the number of nursing events is only 0.24 per hour (Birgersson and Ekvall 1994). The goat hiding phase is more variable, but generally, they are known to have an especially short hiding phase among hider species (Lent 1974; Lickliter 1984). During hiding in the first week, Bungo et al. (1998) reported 5.64 nursing bouts per hour. Thus, goat mothers and kids should interact vocally more often than fallow deer, resulting in a more advanced level of mutual vocal recognition. It is also possible that mutual mother-offspring recognition develops earlier in Bovidae (goats) than Cervidae (fallow deer), or that goats inherited this feature from a common ancestor of sheep and goats (Price et al. 2005).

The differences found between the two hider species studied (goats and fallow deer) could be due an effect of domestication. Our study was carried out on a domestic goat breed; and in the absence of natural predators, there is no obvious selection pressure on offspring to stay hidden. Furthermore, domestic goat kids have fewer opportunities to hide and are often closer to their mothers than they would be in the wild, because of the small sizes of their pens and a lack of suitable hiding places. This could explain the short hiding phase found in domestic goat (Lickliter 1984) and the mutual recognition that we showed resulting from goat kids interacting more often with their mothers and joining social groups earlier. Studying vocal communication and recognition in wild or feral goats living in mountainous areas would be almost impossible, and therefore using captive goats as a model, it is vital for our understanding of cognition in these types of species. Nevertheless, carrying out a study on wild/feral goats would be interesting to test the ecological validity of our results.

Vocal cues to individuality result from inter-individual differences in the vocal production anatomy/physiology or in the way it is operated by individuals (Vannoni and McElligott 2007; Taylor and Reby 2010). Our results show that kid and mother contact calls were individually distinctive. For both kids and mothers, filter-related vocal parameters (formants and energy quartiles) and source-related vocal parameters (F0) accounted for more individuality of contact calls than other parameters (PIC and DFA). According to PIC values and DFA analyses, Jitter, Shimmer and AM-related measures were also important for call individuality in 5W kids and mothers.

The vocal parameters with enough individuality can potentially be used as 'signatures' for individual recognition (Shapiro 2009). The mutual mother-kid recognition shown in our study suggests that mothers and kids memorise these vocal signatures during the first few days following birth. They are then able to decode them in the vocalisations they hear and to use them to discriminate between their own mother/kid calls and calls of familiar individuals from the same social group. Domestic goats in enclosures are constantly within hearing range of others in their groups and, therefore, probably hear familiar individuals as often as their own mothers/kids. The ability to discriminate between familiar and kin vocalisations and respond appropriately, suggests the existence of robust mechanisms of memorisation and recognition.

Cross-validated DFA correctly classified $54.2 \%$ of goat kid calls (mean between $1 \mathrm{~W}$ and $5 \mathrm{~W}$ kids; $60.2 \%$ for males $(n=18)$ and $89.1 \%$ for females $(n=5)$ with the DFAs carried on one kid per mother) and $69.9 \%$ of mother calls. Such percentages are similar to other mammals (e.g. $67 \%$ for calves and $64 \%$ for adult females in Atlantic Walrus, Charrier et al. 2010; 60\% for adult African elephant, Loxodonta africana, Soltis et al. 2005). Because all kids in this study were full or half siblings, and because there is a genetic influence on the structure of goat calls (Briefer and McElligott, unpublished), the percentage of correct classification that we found (54\%) could even have been underestimated. Surprisingly, this correct classification rate is a lot higher than for fallow deer fawns (32.1\%, Torriani et al. 2006). The lack of individuality in fallow deer was suggested to result from age-related changes in morphology and in call structure. Accordingly, we found that the inter-individual variability in kid calls was more important when kids were older (1W males, 52\%; 5W males, 68\%), possibly due to more rapid growthrelated changes in the vocal apparatus at $1 \mathrm{~W}$. Nevertheless, our study shows that ungulate hider offspring can 
have individually distinctive calls even at a young age (1W), with consistent individual variation over time, even when they are still growing.

All male kids in our study were castrated at 3-4 days old. The larynx is a steroid receptor target organ and testosterone can affect it either directly or indirectly by affecting other physical characteristics (body growth, Beckford et al. 1985). Vocal parameters can also be affected by circulating androgen levels (Charlton et al. 2011). Therefore, intact males could potentially have higher individuality due to different levels of testosterone, or lower individuality due to rapid changes to the vocal apparatus driven by direct or indirect testosterone effects than castrated males. However, because testosterone levels in male goats are very low before sexual maturity (i.e. 22 weeks on average; Chakraborty et al. 1989; Ahmad and Noakes 1996), these differences between castrated and intact males are likely to have had little impact on the goats used in our study.

\section{Conclusion}

To conclude, our study showed that mother-offspring vocal recognition in domestic goats, despite being a hider species, is more similar to recognition in follower species (e.g. sheep, Se be et al. 2007) than to recognition in other ungulate hider species (e.g. fallow deer, Torriani et al. 2006). Kid and mother goat contact calls are individualized and mutual mother-offspring recognition is evident from an early age, and probably until weaning. The large differences in the duration of the hiding phase, and in the rate of mother-offspring interactions (possibly partially driven by domestication in some species), could cause variations in the mother-offspring recognition process among hider species.

\section{Ethical note}

Animal care and all experimental procedures were in accordance with the association for the study of animal behaviour ethical guidelines.

\section{Acknowledgments}

We are grateful to E. Antill, C. Booth, E. Cant, C. Charpin, K. Cho Geun-A, C. Farrington, F. Galbraith, L. Kashap, J. Kemp, E. Landy, M. Padilla de la Torre and M. Wang for assistance, and to B. Pitcher, I. Charrier and two anonymous referees for helpful comments on the manuscript. We thank $\mathrm{D}$. Reby for providing the custom built programme in Praat. E. Briefer is funded by a Swiss National Science Foundation fellowship. We acknowledge the financial support of the University of London Central Research Fund. We thank the staff of White Post Farm (http://whitepostfarmcentre.co.uk/) for their help and free access to their animals.

\section{Conflict of interest}

The authors declare that they have no conflict of interest. 


\section{References}

Addae P, Awotwi E, Oppong-Anane K, Oddoye E (2000) Behavioural interactions between West African dwarf nanny goats and their single-born kids during the first 48 hours post-partum. Appl Anim Behav Sci 67:7788

Ahmad N, Noakes DE (1996) Sexual maturity in British breeds of goat kids. Brit Vet J 152:93-103

Aubin T, Jouventin P (2002) How to vocally identify kin in a crowd: the penguin model. Adv Study Behav 31:243277

Beckford NS, Rood SR, Schaid D, Schanbacher B (1985) Androgen stimulation and laryngeal development. Ann Otol Rhinol Laryngol 94:634-640

Birgersson B, Ekvall K (1994) Suckling time and fawn growth in fallow deer (Dama dama). J Zool 232:641-650

Boersma P, Weenink D (2009) Praat: doing phonetics by computer. http://www.praat.org/

Bolker B, Brooks M, Clark C, Geange S, Poulsen J, Stevens M, White J (2009) Generalized linear mixed models: a practical guide for ecology and evolution. Trends Ecol Evol 24:127-135

Bungo T, Shimojo M, Nakano Y, Okano K, Masuda Y, Goto I (1998) Relationship between nursing and suckling behaviour in Tokara native goats. Appl Anim Behav Sci 59:357-362

Caro TM (2005) Antipredator defenses in birds and mammals. University of Chicago Press, Chicago

Chakraborty PK, Stuart LD, Brown JL (1989) Puberty in the male Nubian goat: serum concentrations of LH, FSH and testosterone from birth through puberty and semen characteristics at sexual maturity. Anim Reprod Sci 20:91-101

Charlton BD, Keating JL, Kersey D, Rengui L, Huang Y, Swaisgood RR (2011) Vocal cues to male androgen levels in giant pandas. Biol Lett 7:71-74

Charrier I, Aubin T, Mathevon N (2010) Mother-calf vocal communication in Atlantic walrus: a first field experimental study. Anim Cogn 13:471-482

Craig C (2000) Goldwave v.5.11. St John's, Canada. http://www.goldwave.com/

Fant G (1960) Acoustic theory of speech production. Mouton, The Hague

Fisher DO, Blomberg SP, Owens IPF (2002) Convergent maternal care strategies in ungulates and macropods. Evolution 56:167-176

Hänninen L, Pastell M (2009) Cowlog: open source software for coding behaviors from digital video. Behav Res Meth 41:472-476

Johnson R, Wichern D (1992) Applied multivariate statistical analysis. Prentice-Hall, Englewood Cliffs

Lenhardt ML (1977) Vocal contour cues in maternal recognition of goat kids. Appl Anim Ethol 3:211-219

Lent PC (1974) Mother-infant relationships in ungulates. In: Geist V, Walther F (eds) The behaviour of ungulates and its relationship to management. International Union for the Conservation of Nature and Natural Resources, Morges, pp 14-55 
Lickliter RE (1984) Hiding behavior in domestic goat kids. Appl Anim Behav Sci 12:245-251

Lickliter RE, Heron JR (1984) Recognition of mother by newborn goats. Appl Anim Behav Sci 12:187-192

Louca A, Economides S, Hancock J (1977) Effects of castration on growth rate, feed conversion efficiency and carcass quality in Damascus goats. Anim Prod 24:387-391

McDougall P (1975) The feral goats of Kielderhead moor. J Zool 126:215-246

McGarigal K, Cushman S, Stafford S (2000) Multivariate statistics for wildlife and ecology research. Springer, New York

McGregor P (1992) Playback and studies of animal communication. Plenum Press, New York

Medvin MB, Beecher MD (1986) Parent-offspring recognition in the barn swallow (Hirundo rustica). Anim Behav 34:1627-1639

Miranda-de la Lama GC, Mattiello S (2010) The importance of social behaviour for goat welfare in livestock farming. Appl Anim Behav Sci 90:1-10

Mundry R, Sommer C (2007) Discriminant function analysis with nonindependent data: consequences and an alternative. Anim Behav 74:965-976

O'Brien PH (1988) Feral goat social organization: a review and comparative analysis. Appl Anim Behav Sci 21:209-221

Pitcher BJ, Harcourt RG, Charrier I (2010) Rapid onset of maternal vocal recognition in a colonially breeding mammal, the Australian sea lion. PLoS One 5:e12195

Poindron P, Nowak R, Levy F, Porter RH, Schaal B (1993) Development of exclusive mother-young bonding in sheep and goats. Oxf Rev Repod B 15:311-364

Pollard KA, Blumstein DT (2011) Social group size predicts the evolution of individuality. Curr Biol 21:413-417

Price SA, Bininda-Emonds ORP, Gittleman JL (2005) A complete phylogeny of the whales, dolphins and eventoed hoofed mammals (Cetartiodactyla). Biol Rev 80:445-473

R Development Core Team (2009) R foundation for statistical computing. http://www.R-project.org

Reby D, McComb K (2003) Anatomical constraints generate honesty: acoustic cues to age and weight in the roars of red deer stags. Anim Behav 65:519-530

Reby D, Cargnelutti B, Hewison AJM (1999) Contexts and possible functions of barking in roe deer. Anim Behav 57:1121-1128

Robisson P, Aubin T, Bremond J (1993) Individuality in the voice of the emperor penguin Aptenodytes forsteri: adaptation to a noisy environment. Ethology 94:279-290

Ruiz-Miranda CR, Szymanski MD, Ingals JW (1993) Physical characteristics of the vocalizations of domestic goat does Capra hircus in response to their offspring's cries. Bioacoustics 5:99-116

Se be F, Nowak R, Poindron P, Aubin T (2007) Establishment of vocal communication and discrimination between ewes and their lamb in the first two days after parturition. Dev Psychobiol 49:375-386 
Shapiro AD (2009) Recognition of individuals within the social group: signature vocalizations. In: Brudzynski SM (ed) Handbook of mammalian vocalization-an integrative neuroscience approach. Academic Press, London, pp 495-503

Sokal RR, Rohlf FJ (1995) Biometry: the principles and practice of statistics in biological research. Freeman, New York

Solow A (1990) A randomization test for misclassification probability in discriminant analysis. Ecology 71:23792382

Soltis J, Leong K, Savage A (2005) African elephant vocal communication II: rumble variation reflects the individual identity and emotional state of callers. Anim Behav 70:589-599

Stoddard PK, Beecher MD (1983) Parental recognition of offspring in the cliff swallow. Auk 100:795-799

Sueur J, Aubin T, Simonis C (2008) Equipment review: seewave, a free modular tool for sound analysis and synthesis. Bioacoustics 18:213-226

Taylor AM, Reby D (2010) The contribution of source-filter theory to mammal vocal communication research. J Zool 280:221-236

Tibbetts EA, Dale J (2007) Individual recognition: it is good to be different. Trends Ecol Evol 22:529-537

Titze I (1994) Principles of voice production. Prentice Hall, Englewood Cliffs

Torriani VG, Vannoni E, McElligott AG (2006) Mother-young recognition in an ungulate hider species: a unidirectional process. Am Nat 168:412-420

Trivers RL (1972) Sexual selection and the descent of man. In: Campbell B (ed) Sexual selection and the descent of man. Aldine, Chicago, pp 136-179

Vannoni E, McElligott AG (2007) Individual acoustic variation in fallow deer (Dama dama) common and harsh groans: a sourcefilter theory perspective. Ethology 113:223-234

Wolf CJ, Hotchkiss A, Ostby JS, LeBlanc GA, Earl Gray L Jr (2002) Effects of prenatal testosterone propionate on the sexual development of male and female rats: a dose-response study. Tox Sci 65:71-86 